\title{
LAS FINANZAS DE CUBA EN EL OCASO COLONIAL
}

POR

\author{
FE IGLESIAS GARCÍA
}

Instituto de Historia de Cuba

En este artículo se estudian las repercusiones provocadas por la Guerra de Independencia en el conjunto de la economía cubana, asi mismo se aporta información del costo por sectores, su repercusión sobre las exportaciones, los ingresos aduaneros y el cobro de impuestos, y se traza en líneas generales la situación financiera de Cuba y de los propietarios al momento de iniciarse la reconstrucción del país, a partir del estudio de los gravámenes que afectaban la propiedad.

Los dramáticos relatos de los contemporáneos nos acercan al conocimiento de un hecho evidente: el pueblo cubano pagó un altísimo precio por su independencia. No fueron la sangre derramada, los enormes sacrificios y las vidas de los combatientes los únicos aportes de los cubanos en la lucha por su emancipación. Ya durante la Guerra de los Diez Años la provincia de Camagüey había quedado prácticamente devastada, la de Santiago de Cuba sufrió grandes pérdidas y la de Santa Clara recibió apreciables daños económicos. Pero esas pérdidas son pálidas ante la magnitud de la destrucción que acompañó la Guerra de Independencia ${ }^{1}$.

La economía del país sufrió enormes pérdidas en el curso de la guerra necesaria. La estrategia de lucha llevada a cabo por los revolucionarios, encaminada a destruir la base de sustentación económica de la Colonia, y la consiguiente aplicación de la tea, fueron la causa esencial de la destrucción parcial de la riqueza azucarera y de

1 Ramiro Guerra SÁnchez, Mudos Testigos, La Habana, Editorial de Ciencias Sociales, 1974 y Rafael MARTínez ORTIZ, Cuba; los primeros años de independencia, Habana, Imprenta La Moderna Poesía, 1911. 
varias cosechas de tabaco. Pero la Reconcentración llevada a cabo por Valeriano Weyler, fue la que más contribuyó a la del resto de los cultivos en los que se ocupaban pequeños agricultores y la causa esencial de la estela de muertes y enfermedades que asoló la población civil.

Las autoridades coloniales estaban interesadas en mantener las producciones fundamentales, de aquí que se tomaran medidas para protegerlas, las que no siempre tuvieron el efecto deseado. Es conocido que las producciones cubanas no estaban uniformemente distribuidas, consecuentemente las destrucciones fueron diferentes, en dependencia de la importancia productiva de las regiones. Durante la Guerra de los Diez Años las afectaciones se concentraron en la región oriental debido a que no fue posible llevar las operaciones hacia Occidente, que concentraba las actividades económicas fundamentales. Ésta fue una de las razones que motivaron que la Invasión fuera uno de los puntos más importantes de la estrategia de los revolucionarios.

Se pretendía extender la guerra hacia el oeste como una forma de evitar que la Revolución quedara nuevamente encerrada en la zona oriental. Pero se aspiraba a llevar a cabo otro de los objetivos estratégicos: destruir la base de sustentación económica de la Colonia, que se encontraba todavía, en gran medida, en el occidente del país, aunque ya se había iniciado el desplazamiento hacia el este de la industria azucarera. Igualmente, la producción de tabaco estaba concentrada en el extremo más occidental, aunque había una importante zona productora en el centro de la Isla.

El impetuoso avance de la Invasión y la aplicación de la tea, se evidencian en el testimonio del corresponsal del Louisiana Planter, que escribía en abril de 1896:

"Es imposible ver sin un sentimiento de profunda pena y desesperanza las condiciones de miseria a que la insurrección ha conducido este, antes próspero y rico país. Parece que no se desea poner fin a la total destrucción de fábricas de azúcar, casas de curar tabaco y toda clase de propiedades a través de esta infortunada isla..."2

2 The Louisiana Planter and Sugar Manufacturer (LPSM), New Orleans, Vol. XXII, No. 23, 1899 p. 359.

R. I., 1998, n. ${ }^{\circ} 212$ 
Como esta guerra abarcó todo el territorio, es muy difícil seguir en detalle el curso de los acontecimientos, los reportes de operaciones informan de los ataques a los centros económicos, aunque en ocasiones se especifica el tipo de daño infringido no siempre se puede precisar. Algunas zonas fueron atacadas más de una vez y no todas sufrieron daños que impidieran su recuperación, en ocasiones, se quemaron los sembrados y se interrumpió o impidió la cosecha, pero ésta se pudo restablecer. Independientemente de las destrucciones, el factor que más afectó los cultivos y la población fue el hecho de que ésta fue obligada a abandonar las zonas rurales y, por diversas causas, los terrenos cultivados quedaron abandonados, por lo que era necesario realizar nuevas siembras para lo cual los agricultores carecían de recursos, lo que dificultaba la inmediata recuperación ${ }^{3}$.

Es conocido que ya se había completado la división social del trabajo y la caña era sembrada fundamentalmente por colonos, los que, como se sabe, eran pequeños agricultores. Aunque la quema de un campo de caña no implica necesariamente la destrucción de éste, lo cierto es que la guerra afectó grandemente las siembras; se consideraba que nueve décimas partes de la caña había sido quemada una o más veces. De forma similar ocurrió con las plantaciones de tabaco, segundo renglón de exportación; el ganado, tanto el de cría como el de tiro, fue sacrificado para alimento de ambos ejércitos contendientes o confiscado para transporte de la tropa.

Las fincas también estaban expuestas a otros daños y, en ocasiones, se quemaban las siembras o se tomaba el ganado por parte de las tropas españolas alegando propósitos militares, como en el caso de las propiedades de Cristóbal Madan, que reclamaba por daños sufridos durante la Guerra ante The Spanish Treaty Claims Commission por su ingenio La Rosa, en Jovellanos, se decía que Madan simpatizaba con los insurgentes y les brindaba ayuda. Reclamaba por la quema de sus cañas por las tropas españolas, que alegaron necesidad militar, por lo que Madan fue objeto de discriminación:

"La doctrina de la necesidad militar es aquella que posibilita la destrucción de la propiedad de los neutrales bajo algunas circunstancias ...ésta doctrina se usa como cobertura para la destrucción de propieda-

3 Boletín Oficial de la Capitanía General de la Isla de Cuba, Habana, Año XXXVI, T. IV, 1896, p. 370 . 
des como las practicadas por las tropas españolas contra el Sr. Madan, como muestra el testimonio. A través de todo el caso se aprecia que la hostilidad de los españoles hacia el Sr. Madan y sus compañeros ciudadanos norteamericanos fue el móvil para destruir su propiedad ${ }^{4}$.

En la mayoría de los casos se acusaba a las tropas españolas de negligencia en cuanto a evitar los ataques de los revolucionarios; en general, se les imputa discriminación porque protegían las propiedades de los españoles se ocupaban o usaban indebidamente los centrales de empresas norteamericanas o pertenecientes a cubanos $y$ cubano-norteamericanos.

Los centrales Tuinucu y Narcisa, ambos en Santa Clara, fueron ocupados por las tropas españolas; en la reclamación del primero se calculaba en 70.000.000\$ el valor de los daños causados, además de las pérdidas de caña ${ }^{5}$.

Pero las víctimas fundamentales de la política de guerra de las tropas españolas no fueron las grandes empresas ni los hacendados, el testimonio de Máximo Gómez en 1896 es elocuente:

"...son horribles por su crueldad los hechos por las márgenes del Zaza, acaba de penetrar una columna española que manda el Brigadier Palanca. La familia que ha logrado escapar a tanta matanza, ha sido internándose en los montes ; pero sus casas han sido incendiadas; totalmente destruidas sus labranzas, y sacrificados sus ganados"6.

En carta fechada en Sancti Spíritus el 12 de julio de 1897, se refería al ensañamiento contra los humildes campesinos por parte del tristemente célebre Valeriano Weyler:

"Desamparadas y perseguidas las infelices familias llenas de pavor, muchas se presentan voluntariamente y otras son recogidas violentamente por las columnas. A eso llama el jefe enemigo presentados y a eso también entiende por pacificación"7.

\footnotetext{
4 Before The Spanish Treaty Claims Commission. Washington . s. e. s. a., vol. 18, p. 44.

5 Ibidem. Vol. 11, p. 2.

6 Boletín del Archivo Nacional de Cuba o La Habana, Publicaciones del Archivo Nacional, Vol. XXIII pp. 314-315.

7 Ibidem,Vol. XXX, p. 72.
}

R. I., $1998, \mathrm{n}^{\circ} 212$ 
Varias contingencias obstaculizaron las posibilidades de reconstrucción, a causa de la situación a que había conducido una guerra tan terrible. De hecho, una parte considerable de la población que contribuía directamente a la producción agropecuaria había muerto, fue obligada a abandonar los campos o se había incorporado al Ejército Libertador. Fue necesaria una reorganización de la población y eran pocos los que estaban en condiciones físicas de trabajar al finalizar la Guerra. A pesar de éstos y otros obstáculos, el proceso de reconstrucción fue bastante acelerado si se tiene en cuenta la magnitud de la devastación.

Los efectos de la Guerra sobre el sector azucarero y sus relaciones con el proceso de concentración que se venía produciendo, se han investigado con mayor detalle en un trabajo anterior ${ }^{8}$.

En este estudio no se pretende realizar un análisis minucioso de las destrucciones de la Guerra de Independencia, solamente se aspira a examinar los efectos de la contienda sobre la economía global. Interesa detectar hasta qué punto y en qué forma la Guerra afectó el conjunto de la economía, para trazar, en la medida de lo posible, las líneas generales de la situación financiera de la Isla y de los productores al momento de iniciarse la reconstrucción del país, a fin de valorar su punto de partida.

En un informe del mes de abril de 1896, se hacía una interesante predicción; se decía que en marzo de ese año se estimaba que las pérdidas causadas por la insurrección ascendían a $150.000 .000 \$$, a lo que se debía añadir el incremento de la Deuda de Cuba desde marzo de 1895 hasta el 31 del mismo mes en 1896, que fue de $15.000 .075 \$$ y se resumían los efectos en:

\begin{tabular}{lc}
\hline DAÑOS DE LA INSURRECCIÓN & $15.500 .075 \$$ \\
\hline DEUDA PREVIA DE CUBA & $163.551 .950 \$$ \\
GRAN TOTAL & $468.582 .025 \$$ \\
\hline
\end{tabular}

4 Fe Igesias García, Del ingenio al central, San Juan, Eds. de la Universidad de Puerto Rico (en prensa). 
Y se añadía: “... si la guerra continúa no cabe duda que Cuba será responsable de una deuda mayor de 500.000.000\$9, lo que se cumplió ${ }^{10}$, la Deuda se desglosaba en 1898 en:

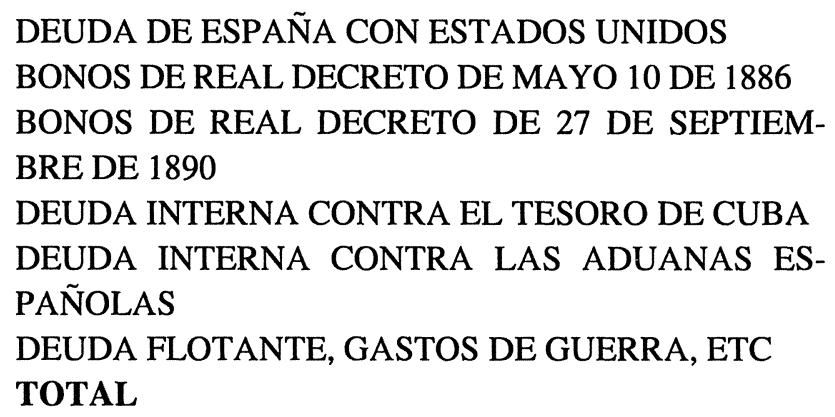

Fuente: Robert PORTER, Industrial Cuba New York, G. P. Putnams Sons, 1899 , p. 259"11.

Finalizada la contienda se calculaba que:

"El valor total de las propiedades perdidas como consecuencia de la guerra se estima en 500 millones dólares, en números redondos, y la Isla necesitará ser provista de capital extranjero que venga que en cantidad mayor que antes y en seis o siete años para recuperar su anterior prosperidad"12.

9 Véase, [2], Vol. XVI, $\mathrm{n}^{\circ} 15$, p. 230.

10 Félix Iznaga, Ecos del Tratado de París. La Deuda Colonial, Habana, Edición de "Cuba Contemporánea", Imprenta "El Siglo XX", 1911.

11 En 31 de diciembre de 1897, según cuentas publicadas por El Economista la deuda de Cuba se descomponía de la siguiente forma:
Billetes hipotecarios de 1888 .
Billetes hipotecarios de 1890
118.010 .200
Obligaciones de Aduanas
171.710 .000
143.300 .000
Atrasos pendientes de pago
60.000 .000
Deudas no convertidas, abonarés y reclamaciones
15.000 .000
Billetes del Banco Español que carecen de garantía metálica
14.000 .000
TOTAL
522.020 .200

Pesos

Fuente: Elena HeRnÁNDEZ SANDOICA y M. Fernanda MANCEBo. "Financiación de una guerra colonial (Cuba: 1895-1898) y opinión pública en la España del XIX”, Estudios dedicados a Juan Peset Aleixandre. Universidad de Valencia, 1982, pp. 400-401.

12 Véase [2], Vol. XXII n ${ }^{\circ} 25,1899$. p. 395.

\section{R. I., $1998, \mathrm{n}^{\circ} 212$}


La información pormenorizada, a partir de cálculos conservadores, de los daños causados hasta finales de abril de 1896, evidencia que, consecuentemente con su peso en la economía, fue la industria azucarera la que más sufrió.

\section{DAÑOS CAUSADOS POR LA INSURRECCIÓN}

EN DÓLARES

$\begin{array}{lr}\text { A la producción azucarera } & 50.000 .000 \\ \text { A la producción tabacalera } & 12.000 .000 \\ \text { Daños a ferrocarriles } & 10.000 .000 \\ \text { Daños a plantaciones de tabaco y otras } & 8.000 .000 \\ \text { Daños a fábricas azucareras } & 6.000 .000 \\ \text { Destrucción de propiedades del Gobierno } & 3.000 .000 \\ \text { Destrucción de propiedades privadas } & 18.000 .000 \\ \text { Pérdidas de caballos y mulos } & 3.500 .000 \\ \text { Descenso en valores públicos } & 20.000 .000 \\ \text { Paralización de negocios e industrias de todas clases } & 15.000 .000 \\ \text { TOTAL } & \mathbf{1 5 0 . 0 0 0 . 0 0 0}\end{array}$

Más del $37 \%$ de las pérdidas computadas correspondían a la producción de azúcar; aunque estos cálculos son bastante conservadores. Si se tiene en cuenta el azúcar dejado de producir las pérdidas son muy superiores ${ }^{13}$.

Cómputos de la época estimaban una ganancia líquida de 2,00\$ por cada saco de azúcar de 320 libras; si se supone que el mínimo producido podían ser 900000 toneladas por año, el valor neto de lo que se pudo alcanzar sería de 63.000.000\$, y durante los tres años se produjo azúcar por un valor neto calculado de $11.438 .910 \$$, lo que representa el 18,2\% del valor posible obtenido durante los años de guerra, aunque los $2,00 \$$ de ganancia por saco de azúcar es una cifra muy elevada para las condiciones en que se llevaban a cabo las zafras azucareras durante la contienda.

13 Véase [2], Vol. XVI, n. ${ }^{\circ}$ 13, 1896, p. 200. 
El Comisionado Especial de los Estados Unidos a Cuba, Robert Porter, expresaba en cuanto a las pérdidas:

“... Dañadas a tal punto que la producción alcanzó solamente 225.221 toneladas, la más baja en 50 años. Este decrecimiento no se produjo en forma gradual, de modo que permitiese al país, a los negocios y a las personas ajustarse al cambio de circunstancias, sino que todo ésto aconteció casi en una noche, de un ingreso por concepto de azúcar de 80.000.0000\$ al año, disminuyó a 16.000.000\$, una rebaja, por tanto de $64.000 .000 \$[\ldots . . .]^{\prime \prime 14}$.

Estas cifras se refieren al producto bruto de la industria azucarera y representan estimados, es interesante ver más en detalle esta cuestión, porque es la forma más objetiva de evaluar el problema en términos de valor. Parece que será imposible hacer un cálculo preciso de los daños materiales, además de que un factor esencial es la drástica reducción de los productos de exportación, elemento fundamental de todas las reclamaciones por daños de guerra ${ }^{15}$.

El análisis del comercio exterior de Cuba con Estados Unidos, que era el principal importador de la Isla, evidencia una tendencia decreciente a partir de 1895 hasta a llegar bajar en 1898 el 71,2 \% del total exportado en 1890. La caída más grave la experimentó el saldo comercial, que fue del $85,7 \%$, el que había sido altamente favorable hasta 1896. También se produjo un brusco descenso en cuanto a la participación de la industria azucarera en el valor total de las exportaciones a Estados Unidos, del $84 \%$ en 1894 al $60 \%$ en $1899^{16}$.

Aunque el comercio con España era de escasa importancia también se vio afectado en cuanto a las exportaciones a la Metrópoli, no así en cuanto a las importaciones. Es muy elocuente el hecho de que las importaciones crecieron en el $17,9 \%$ entre 1891 y 1896 , mientras las exportaciones decrecían en $41,5 \%$ de 1894 a 1896. Pero más significativo es el incremento de la balanza desfavorable para la Colonia, que fue del $46 \%$ entre 1891 y 1896 . Los exportado-

\footnotetext{
14 Robert Porter, Industrial Cuba, New York, G. P. Putnams Sons, 1899, p. 281

15 Committee on Relations whith Cuba, Cuban Sugar Sales 57th Congres 1st. sess. (Washington 1902), p. 396.

16 Calculado sobre la base de los datos de Manuel Moreno Fraginals,. El Ingenio, 3 Ts, La Habana, Editorial de Ciencias Sociales, 1978, T. III, p. 85.
} 
res españoles no dejaron de beneficiarse con el comercio cubano aun en circunstancias de guerra ${ }^{17}$.

Es conocido que los aranceles, sobre todo los de importación, representaban los ingresos fundamentales para las cajas cubanas. El análisis de los derechos cobrados por las aduanas coloniales entre 1890 y 1898 arroja resultados muy esclarecedores: mientras los derechos de importación descendieron el $34 \%$ entre 1890 y 1897 , los de exportación se redujeron en el $66 \%$ en igual período ${ }^{18}$.

En concordancia con la baja de las producciones fundamentales se afectaron los ingresos aduaneros por derechos de exportación; en cuanto a los aranceles de importación es interesante destacar que la caída no fue tan brusca, muy probablemente atenuada por el incremento de los aranceles en el 5\% del valor oficial de las mercancías importadas partir de 1896. Las cifras de impuestos generales cobrados por el Banco Español de la Isla de Cuba, encargado de las recaudaciones desde 1886, son mucho más elocuentes.

IMPUESTOS RECIBIDOS POR EL BANCO ESPAÑOL $1889-1890$ A $1897-1898$

\begin{tabular}{ccc}
\hline AÑOS & COBRADO & ÍNDICE \\
\hline $1889-1890$ & $4.304 .207,16$ & 100.0 \\
$1890-1891$ & $4.659 .477,25$ & 108.3 \\
$1891-1892$ & $3.696 .877,74$ & 85.9 \\
$1892-1893$ & $4.635 .278,61$ & 107.7 \\
$1893-1894$ & $4.507 .920,29$ & 104.7 \\
$1894-1895$ & $4.425 .338,49$ & 102.8 \\
$1895-1896$ & $3.539 .029,98$ & 82.2 \\
$1896-1897$ & $3.266 .583,37$ & 75.8 \\
$1897-1898$ & $2.377 .742,21$ & 55.2 \\
\hline
\end{tabular}

Robert PORTER, Industrial Cuba, New York, G. P. Putnams Sons, 1899, p. 253.

17 William Clark, Commercial Cuba New York, Charles Scribers Sons, 1898, p. 242.

18 Robert PORTER, [14], pp. 36-37, 38. 
El descenso fue de cerca del $50 \%$ y el impuesto sobre fincas rústicas sufrió una brusca caída, ya que se redujo en el $86 \%$ entre 1890 1891 y $1897-1898^{19}$.

Desde marzo de 1896 el Círculo de Hacendados se dirigía al Gobernador General y argumentaba:

“... en estas condiciones parece evidente que se impone la exención del pago en las contribuciones al Estado y a los Municipios, la cual si merma en algo los ingresos del Tesoro,... Sin contar con que esa exención más que alivio, representaría la satisfacción de una necesidad ineludible, ya que no existe posibilidad de efectuar esos pagos"20.

Todavía el 28 de Mayo de 1897 se dispuso que:

"Durante el ejercicio de 1897-1898 regirán en la isla de Cuba los presupuestos generales del Estado puestos en vigor por la ley de 28 de Junio de 1895, con las modificaciones acordadas posteriormente en cumplimiento de preceptos legales"21.

Por lo que en el anteproyecto de presupuesto para el año de 1897 a 1898 se proponían ingresos por un importe de 30.620 .349 pesos y 78 centavos, para cubrir una cifra de gastos de 37.921 .845 pesos con 48 centavos. Casi el total del aumento de gastos correspondía a las obligaciones generales y las secciones de Guerra y de Marina, y se destinaba mayor importe del servicio de la Deuda. A pesar de que "aún descartadas las obligaciones de la campaña, para las cuales existe, concedido por las Cortes, un crédito ilimitado y permanente que se nutre sin dificultad con ingresos obtenidos del crédito público"22.

En el editorial de El País se abogaba por la supresión de la contribución para 1898-1899 ya que:

"Los propietarios de fincas rústicas se encuentran en una situación excepcional, pues si bien disfrutan de aquellas condonaciones por sus adeudos de 1895-1896 a 1897-1897, se hallan sin haber podido aún re-

\footnotetext{
19 Ibidem. p. 252.

20 Biblioteca del Ministerio del Azúcar de Cuba Círculo de Hacendados Actas

${ }^{21}$ Revista de Contribuciones e Impuestos. Año I, N ${ }^{\circ}$ 3, La Habana, 24.6.97, p. 32.

22 Idem.
} T. VIII. 
construir sus fincas y con los recibos del presente ejercicio de 18981899 al cobro, imponiéndose por iguales causas su condonación”23.

Demasiado tarde se aceptó una aplastante realidad reconocida en el acuerdo de las cámaras insulares, sancionado por el Gobernador General el 23 de julio de 1898 que en el presupuesto de la Isla para el ejercicio de 1898-1899:

\footnotetext{
"fueron condonados en su totalidad los débitos pendientes de cobro de los ejercicios de 1895-1896, 1896-1897 y 1897 a 1898 correspondientes a fincas rústicas cuyas fábricas y frutos hayan sido completamente destruidas por la guerra o perdidos sus frutos en mayor cantidad de las tres cuartas partes con relación a los producidos en 18994-1895 y condonación de un 25 por 100 en los descubiertos, también por fincas agrícolas y por igual período y que no se hallen en los casos anteriores" 24 .
}

En esta ocasión ya que no podían sacar de Cuba los recursos para costear la guerra a España no le quedó otra alternativa que asumir su responsabilidad económica. En marzo de 1898 Carlos M. Trelles envió a la revista Cuba y América sus cálculos sobre la situación financiera española ${ }^{25}$.

Elena Hernández Sandoica y M. ${ }^{\mathrm{a}}$ Fernanda Mancebo reconocen que: "Los gastos de la guerra son dificiles de precisar con exactitud", reproducen estimados de un costo total entre más de mil y $750 \mathrm{mi}-$ llones de pesos y detallan varias partidas que representan cifras muy superiores a los cómputos de Trelles ${ }^{26}$.

Las grandes perturbaciones financieras que sufrió Cuba durante los últimos treinta años del ochocientos fueron provocadas por la enorme deuda cargada sobre las cajas cubanas, el aumento de ésta se produjo durante la Guerra de los Diez Años, pero no fue amortizada, al contrario, se incrementaba para cubrir déficits de los presupuestos y otras atenciones. Una nueva emisión de billetes sobre base plata y el bando de Valeriano Weyler del 28 de agosto de 1896, que ordenaba el curso forzoso de los billetes, ya muy depreciados ${ }^{27}$.

\footnotetext{
23 Idem.

24 El País, Año XXI, Nº 300, La Habana, 18.12.98.

25 Idem.

26 Elena Hernández Sandoica y M. ${ }^{a}$ Fernanda Mancebo [11], pp. 375-408

27 Véase [3] Año XXXVI, Nº 30, T. 3, 1896, p. 573.
} 
Debido a las dificultades ocurridas en las transacciones diarias el Banco Español de la Isla de Cuba, consecuente con su política al servicio de los intereses estatales, emitió en 1896, 10.000 .000 en moneda para cubrir los gastos de guerra, el agio se incrementó ${ }^{28}$.

Cuba arribó al final de la guerra con graves perturbaciones monetarias, Robert Porter informaba que estaba afligida por muchas clases de moneda depreciada y sentenciaba:

\footnotetext{
"Ningún país puede ser próspero permanentemente si su moneda no es estable y su crédito bueno. Mal manejo de las finanzas estatales trae consigo mal crédito y crédito inestable es la causa de moneda depreciada. También Cuba está afligida por muchos tipos de monedas depreciadas"29.
}

Las dificultades con el crédito y las perturbaciones financieras no son consecuencias solamente de la Guerra de Independencia, aunque la situación de los propietarios endeudados se hizo más difícil. Cuba carecía de bancos en el verdadero sentido de la palabra y los propietarios que no poseían capital acumulado o desarrollaban su actividad en esferas como el comercio, se veían obligados a recurrir al usurero, por lo que la mayor parte de la propiedad territorial estaba afectada por diferentes tipos de gravámenes. La Guerra solamente contribuyó a agravar aun más su situación, la más penosa consecuencia fue la pérdida de las propiedades por aquéllos que no pudieron saldar los créditos e intereses acumulados.

En enero de 1895 el Gobierno General envió un telegrama al Ministro de Ultramar en que solicitaba un crédito del Banco de España por cinco millones de pesos para pignorar la $\mathrm{zafra}^{30}$. Todavía en diciembre de ese año numerosos hacendados y colonos promovieron el establecimiento de un banco azucarero y solicitaron del Gobierno que autorizara al Banco Español de la Isla de Cuba para que realizara una emisión a cargo del tesoro de la Isla y del Tesoro Nacional por valor de 20.000 .000 de pesos en billetes que debían ser recibidos por todo su valor en el pago de impuestos y aranceles. Se solicitaba que fueran dos series de 10.000 .000 de pesos cada una y que una de ellas fuera para uso exclusivo de los hacendados, pagade-

\footnotetext{
28 [2] Vol. XVII, n ${ }^{\circ} 16,1896$, p. 246.

29 R. PORTER [14]

30 [20] T. VI.
}

R. I., $1998, \mathrm{n}^{\circ} 212$ 
ros al Banco Español y para asistir al comercio en general. Nunca fue autorizado ${ }^{31}$.

En instancia del Círculo de Hacendados al Gobierno General del primero de marzo de 1896 se exponía:

"Que la asoladora guerra que devasta el país, ha venido a colocar a los hacendados en una situación verdaderamente insostenible, que urge remediar en el acto, no sólo para aminorar el estrago causado, sino para evitar la total desaparición de la más importante industria de la Monarquía"32.

Se solicitaba la exención en el pago de contribuciones al Estado y a los municipios y la suspensión de todo procedimiento judicial contra hacendados, mientras oficialmente no se declare la paz pública, limitando el interés ya pactado al tipo legal ${ }^{33}$.

En respuesta a la solicitud del Círculo de Hacendados se publicó el decreto de 15 de mayo de 1896 que prorrogaba créditos hipotecarios vencidos o que vencieran hasta el 30 de abril de 1897, suspensión de juicios para el cobro de los créditos y los réditos de censos suspender el apremio a bienes inmuebles, pero continuación de procedimientos de adeudos al Estado ${ }^{34}$.

En la instancia presentada por el Círculo el 12 de diciembre de 1897, se solicitaba la prórroga por un año más del plazo concedido para el pago de créditos, reducción de los derechos adicionales a los productos extranjeros en la reforma del arancel propuesta, negociar un tratado de reciprocidad con Estados Unidos, condonación de las contribuciones adeudadas por los dueños de fincas rústicas destruidas, abandonadas o que no hayan estado en producción a causa de la situación de guerra, entre otras medidas ${ }^{35}$.

Aunque la propiedad estaba protegida de los embargos, se produjo una paralización de los créditos, no obstante, el 5 de marzo de 1898, Ramón Blanco dispuso la prórroga en todas sus partes hasta el

\footnotetext{
31 [2] XV, $n^{\circ} 24,1895$, p. 379 y Vol. XVI, nº 1, 1896, p. 9.

32 [20] T. VIII.

33 Idem.

${ }^{34}$ Gaceta de La Habana, La Habana, Año LVIII, $n^{\circ}$ 117, T. I, 17.5.96, p. 929.

35 [20] T. VIII.
} 
31 de marzo de 1899 del decreto del Gobierno General de abril de 1897 , relativo a la suspensión de procedimientos de apremio ${ }^{36}$.

Un proyecto de ley de crédito agrícola fue presentado por el Secretario de Agricultura, Industria y Comercio del Gobierno Autonómico ${ }^{37}$. Varios representantes propusieron la creación de un banco territorial hipotecario ${ }^{38}$; era una utopía plantearse la creación de una institución de esa naturaleza cuando los propios ponentes reconocían las dificultades que imponían las circunstancias de guerra. Pero es que en condiciones normales ni en momentos de prosperidad fue posible estabilizar el sistema bancario de la Isla.

Concluida la guerra, el Círculo de Hacendados presentó un proyecto en que se proponía que los créditos de todas clases vencidos con anterioridad a diciembre de 1898 o que vencieran en lo sucesivo, no se pudieran hacer efectivos sobre fincas que fueron destruidas total o parcialmente y aquellas cuya producción hubiese disminuido después de la Revolución en más del $50 \%$ de lo logrado antes del inicio de la contienda ${ }^{39}$.

Se estimaba que éste era otro factor más que había contribuido poderosamente a la ruina de los propietarios de Cuba: "con la consecuencia de que hoy hay millones de dólares en interés que no se han pagado" 40 . El 24 de abril de 1899 se decretaron dos años de prórroga, que concluían el primero de marzo de 1901, para el cobro con garantía de la propiedad inmueble, que alcanzaban las contraías después del 31 de diciembre de $1898^{41}$.

El Louisiana Planter informaba que la medida se había hecho necesaria debido a las dificultades en que se encontraban la mayoría de los hacendados y que había recibido la aprobación general de éstos pero:

36 [34] Año LX, no 61, t. I, 1898, p.515,

37 Archivo Nacional de Cuba, Gobierno Autonómico, 4/48.

38 En primer término ocurre preguntar si es oportuno en los actuales momentos tratar de la creación de una institución de crédito, cuando subvertido el orden social por una guerra asoladora, ha sucumbido la mayor parte de la riqueza acumulada por el trabajo de cuatro centurias, y aparecen envueltas en densas nieblas la vida presente y el porvenir de esta Colonia. En tales condiciones sobre qué bases habrá de sustentarse una institución de crédito cuya vida y cuyo desarrollo, por su propia naturaleza, exijen la estabilidad de las instituciones generales y la normalidad en el curso de los negocios. Ver Gobierno Autonómico [37], 5/22.

39 [20] T. VIII.

40 [2] Vol. XXI, $n^{\circ} 25,1898$, p. 394.

41 [20] T. VIII. 
“... Se ven compelidos a añadir a sus créditos otro año de intereses y es probable que cuando llegue el momento de liquidar las deudas de forma definitiva, los precios a que se vendan los centrales hipotecados solamente serán suficientes para cubrir el total de la deuda, debido a la enorme acumulación de intereses"42.

En un trabajo realizado para conocer el estado de la propiedad territorial de la Isla, se corroboró el alto grado de endeudamiento de los propietarios. A esta situación se había llegado por un largo proceso que se inició desde los primeros siglos de la colonia en los que la forma más común del crédito era la imposición de censos sobre la propiedad rústica, a lo que se añaden aquéllos a favor de instituciones religiosas. Una parte de la tierra adquirida durante la primera mitad del siglo XVIII por pequeños cultivadores fue también comprada a censo.

Las hipotecas fueron también el producto de un largo proceso. La ausencia de un sistema de crédito condicionó la necesidad de hipotecar las fincas, casi siempre con el refaccionista, para la obtención de recursos que posibilitaran financiar los costos de producción y la adquisición de esclavos y trabajadores contratados, asiáticos o de otra procedencia. Muchas deudas no pudieron ser saldadas y así la propiedad inmueble llegó a fines de siglo con una pesada carga, que hacía aun más difícil la reconstrucción ${ }^{43}$.

En 1900 se publicaron los datos estadísticos sobre el monto de las hipotecas y censos que afectaban la propiedad. No hay coincidencia en cuanto a las cifras, pero se evidencia la grave situación en que se encontraba la propiedad rústica:

GRAVÁMENES QUE AFECTABAN LA PROPIEDAD INMUEBLE CUBA 1900

\begin{tabular}{lccc}
\hline FINCAS & CENSOS PESOS & HIPOTECAS PESOS & TOTAL PESOS \\
\hline Urbanas & 14.608 .850 & 100.729 .940 & 115.338 .790 \\
Rústicas & 25.679 .452 & 106.897 .249 & 132.576 .701 \\
Total & 40.368 .302 & 207.627 .189 & 247.915 .941 \\
\hline
\end{tabular}

Fuente: Revista de Agricultura, La Habana, Año XVI. Número extraordinario, (15 de octubre de 1900), p. 3.

42 [2] Vol. XXII, n 14, 1899, p. 217.

43 Cuba. Gobernador Militar. Civil Report 1899-1900, La Habana, 1901, T. 7, pp. 163, $210,239,282,293$. 
Recién conocidos los datos se manifestó:

“... ya sabemos que la propiedad inmueble de Cuba debe la fabulosa cantidad de 248 millones de pesos oro, es decir, más que la deuda pública de algunos Estados y tanto como la famosa deuda exterior de España en Cuba que, para muchos, impedía todo intento de posible regeneración financiera" 44 .

Se expresaba la preocupación de que la mayoría de las hipotecas afectaba la media y pequeña propiedad; que casi todos los vegueros de Vuelta Abajo tenían deudas, que en el antiguo distrito azucarero de Cárdenas solamente 16 fincas debían más de $100.000 .00 \$$, mientras 391 tenían gravámenes por menos de 20.000. Se destacaba que Cienfuegos: "que es zona esencialmente azucarera, asiento de los más grandes centrales, aparece la comarca más desempeñada de la Isla, desmintiendo la opinión corriente de que los hacendados son los entrampados..." Se aseveraba que los que más debían eran colonos, vegueros y sitieros ${ }^{45}$.

La información pormenorizada por provincias fue publicada en el informe del Gobernador Militar, pero se excluían los datos de la antigua provincia de Santiago de $\mathrm{Cuba}^{46}$. Se ha preferido reproducir los datos publicados en la memoria del Censo de 1899, que tiene como base los acopiados por la Secretaría de Hacienda, en 1900 porque incluyen la provincia de Santiago de Cuba, además del valor aproximado de la propiedad, aunque se advierte que el valor de los bienes raíces era muy superior al consignado:

"Al discutir estas proporciones no debe olvidarse que desde la ocupación americana no ha habido una tasación debida de los bienes raíces, y que las cifras que se citan son las que dieron los empleados españoles algún tiempo antes de dicha ocupación"47.

\footnotetext{
44 Revista de Agricultura, La Habana Año XVI, N 1, 1900, p. 2.

45 Idem.

46 Departamento de la Guerra. Oficina del Director del Censo de Cuba. Informe sobre el Censo de Cuba, 1899. Washington, Imprenta del Gobierno, 1900, p. 45.

47 [44], 15.10.1900. Número Extraordinario, p. 3.
}

R. I., $1998, \mathrm{n}^{\circ} 212$ 
BIENES RAÍCES RURALES

\begin{tabular}{lccrr}
\hline \multicolumn{1}{c}{ PROVINCIA } & $\begin{array}{c}\text { VALOR DE LA } \\
\text { PROPIEDAD }\end{array}$ & HIPOTECAS & CENSOS & TOTAL \\
\hline Pinar del Río & 28982950 & 8080998 & 4833793 & 12914791 \\
Habana & 44140610 & 18797063 & 7037047 & 25834110 \\
Matanzas & 45.594 .977 & 35.754 .485 & 9.178 .964 & 44.933 .449 \\
Santa Clara & 41.838 .395 & 37.422 .559 & 3.445 .936 & 40.868 .495 \\
Puerto Príncipe & 3.446 .736 & 2.706 .196 & 984.795 & 3.690 .991 \\
Santiago de Cuba & 20.701 .166 & 4.135 .946 & 188.915 & 4.32 .4861 \\
Total & $184.724 .834^{*}$ & $106.897 .247 *$ & $25.669 .450 *$ & 132.566 .679 \\
\hline
\end{tabular}

* Error de suma en el original.

Fuente: DePartamento DE GuerRA, Oficina del Director del Censo de Cuba. Informe sobre el Censo de Cuba, 1899. Washington, Imprenta del Gobierno, p. 44.

Los parciales coinciden con los publicados en el informe del Gobernador Militar para las provincias de Pinar del Río hasta Puerto Príncipe. Si se calcula el por ciento de los gravámenes con relación al valor estimado de la propiedad, se obtienen datos muy interesantes para el estudio de las diferentes provincias; es significativo el bajo valor que se le calculaba a la propiedad rústica de la antigua provincia de Puerto Príncipe. Es que no hay que olvidar que la tierra incrementa su precio en la medida en que sea cultivada y, como se sabe, ésa era la provincia con más tierra inculta en el país.

GRAVÁMENES SOBRE LA PROPIEDAD RÚSTICA. 1900

\begin{tabular}{lcrc}
\hline \multicolumn{1}{c}{ PROVINCIA } & $\begin{array}{c}\text { VALOR DE LA } \\
\text { PROPIEDAD }\end{array}$ & GRAVÁMENES & \% DEL VALOR \\
& 28.982 .950 & 12.914 .791 & 44,6 \\
\hline Pinar del Río & 44.140 .610 & 2.583 .411 & 58,5 \\
Habana & 45.594 .977 & 4.493 .3449 & 98,5 \\
Matanzas & 41.838 .395 & 40.868 .495 & 97,7 \\
Santa Clara & 3.446 .736 & 3.690 .991 & 106,4 \\
Puerto Príncipe & 20.701 .166 & 4.135 .946 & 20,9 \\
Santiago de Cuba & 184.724 .843 & 132.566 .697 & 77,7 \\
Total & & & \\
\hline
\end{tabular}

Fuente: Departamento de Guerra, Oficina del Director del Censo de Cuba. Informe sobre el Censo de Cuba, 1899. Washington, Imprenta del Gobierno, p. 44. 
Aunque esta información tiene las deficiencias ya apuntadas, es significativo que las dos provincias más endeudadas fueran Matanzas y Santa Clara, en las que se concentraba el centro fundamental de la producción azucarera. El caso de Puerto Príncipe se explica por una subvaloración de la propiedad, aunque no deja de ser sumamente interesante. Al monto total de lo adeudado había que añadir los intereses de las hipotecas y los réditos de los censos, que se habían acumulado sobre todo a partir de las sucesivas moratorias y se estimaba que: "..no es aventurado asegurar que importarán otra suma igual" 48 .

Se consideraba que:

"Esta enorme carga que pesa sobre la propiedad cubana es el más poderoso obstáculo para la reconstrucción del país, hasta el punto que ningún capitalista está dispuesto a entrar en transacciones de ningún tipo con los propietarios de centrales tan fuertemente hipotecados; y los plantadores que han tenido la suerte de salvar sus plantaciones están ahora tan necesitados de dinero como aquellos a los que les fue destruida, el proceso de la reconstrucción agrícola será extremadamente difícil, las hipotecas existentes en la propiedad rural son una pesada carga no solamente porque el dinero ha alcanzado por cientos muy altos de interés, generalmente superior al $10 \%$, pero también porque la mayoría de esas hipotecas están ahora vencidas"49.

\section{Los pronósticos eran en extremo pesimistas:}

"...Cuando venga el día que los poseedores de esas hipotecas estén autorizados a tomar acción por recuperar el dinero adelantado, acción que ha sido evitada primero por el gobierno español y luego por el de Estados Unidos, un número de hacendados y cultivadores serán inevitablemente arruinados y propiedades que valen entre $150.000 \$$ y 200.000.00\$ serán sacrificadas para cubrir deudas de 50.000.00\$, 40.000.00\$ y hasta menos de 30.000.00\$. La disposición decretada por el gobierno de Estados Unidos y de España lo que ha hecho es prolongar la agonía de los infortunados que están incapacitados para obtener dinero y son impedidos de poner sus centrales en estado de producción, si están inhabilitados para procurar fondos por ellos mismos, se

48 Ibidem.

49 [2] Vol. XXIV, $\mathrm{n}^{\circ} 12,24.3,1900$, p. 185.

R. I., 1998, n. 212 
debe a que la gente no desea adelantar fondos a propietarios anteriormente hipotecados... ${ }^{50}$.

En el Proyecto de Reconstrucción del País del Círculo de Hacendados firmado por Manuel Froilán Cuervo, publicado en un número especial de la Revista de Agricultura en 1900, se expresaba: "Hoy nuestras tierras están embrolladas y sometidas a innúmeros gravámenes que nacieron bajo el viejo régimen hipotecario".

La prórroga del decreto que suspendía la acción legal para el cobro de créditos bajo hipoteca sobre propiedades en Cuba expiraba el día 30 de diciembre de 1900. La situación era indudablemente muy seria y se demandan medidas urgentes y eficaces para conciliar los intereses de deudores y acreedores ${ }^{51}$.

El periódico Patria abogaba por una solución a favor de los deudores, señalaba que: "es un hecho conocido por todos los que se hallan relacionados con la industria azucarera del país, que la producción en el año 1896 no hubiera sido inferior á la suma de 1.200.000 toneladas". Por lo que en la últimas tres zafras se pudo haber producido un total de 3.600.000 toneladas. Se calculaba un total producido de 742.815, por lo que se habían dejado de elaborar cerca de 2.857.185, las que a un cálculo oderado de $40.00 \$$ cada una, representaban 114.287.400.00\$, se estimaba un $75 \%$ de gastos, por lo que quedaría un producto líquido de $\$ 28.571 .850$ y una parte de ello podría haberse dedicado al pago de deudas pendientes, pero:

\footnotetext{
"La guerra no sólo impidió dicha producción, sino que devastó los campos, destruyó cercas, edificios, maquinarias, quemó las carretas y los aperos de labranza, dispuso de los bueyes con más o menos violencia. Y las fincas que quedaron en pié reducidas a la mera existencia de un batey, representan un esfuerzo inaudito y de constante peligro, que se tradujo en crecidos gastos extraordinarios.

En esas condiciones se sale de la guerra. Surge desde luego el problema de la reconstrucción del país. Bajo las garras de la miseria nada progresa: la vida languidece y se extingue. La voluntad se embota, el esfuerzo se paraliza, la inteligencia se apaga" 52 .
}

\footnotetext{
50 Ibidem.

51 [2 ] Vol. XXIV, nº 19 12. 5., 1900, p. 297

52 Patria, La Habana, Marzo 9, 1899.
} 
El articulista argumentaba que: "Si el derecho del acreedor hubiera revestido forma tangible, habría quedado también sepultado bajo las ruinas de algunas casas de calderas o se habría evaporado con el humo de una campo de caña o de una vega de tabaco. Y que: ...El acreedor no es el único ser con derecho a la vida, aún cuando, según uno de los comerciantes que ha terciado en estos debates, su derecho, en ese terreno, sea mejor que el del deudor" 53 .

Comisionados de los hacendados intercedieron en Washington para obtener una prórroga de diez años, alegaban que necesitaban un mínimo de tres años para reponerse pero:

"Es sabido que el esfuerzo del comité será en vano, ya que es bien conocido que poderosos sindicatos se han organizado en New York, con el objetivo de adquirir en Cuba tantos centrales azucareros y otras propiedades como les sea posible. El plan de estos financieros consiste en ejercer presión sobre el Presidente McKinley para que no intervenga en el asunto de la extensión del plazo en que se deban pagar las hipotecas. Bajo este esquema un gran número de valiosas plantaciones serán vendidas por ejecución y los sindicatos las podrán adquirir por la mitad o menos de su actual valor" 54 .

Todo lo cual hacía considerablemente compleja la situación de la propiedad rústica cubana $\mathrm{y}$, aunque casi todos los propietarios rurales estaban endeudados siempre los más débiles sufrían las peores consecuencias: "Los pequeños propietarios, los que están en más íntimo contacto con la tierra, aquellos menos contaminados con el afán de la ciudad son los que más deben"55.

Lo que los hizo extremadamente vulnerables ante las empresas y especuladores norteamericanos que tenían como uno de sus objetivos priorizados apoderarse de la mayor cantidad de tierras útiles para la producción azucarera. Tanto pequeños agricultores como hacendados sufrieron las consecuencias de su situación indefensa ante la avalancha de inversionistas, que venían a adquirir una propiedad rústica depreciada por el peso de las deudas y la destrucción que había sufrido en una guerra devastadora.

\footnotetext{
53 Idem.

54 [2] Vol. XXII, $\mathrm{n}^{\circ} 17,1899$, p. 267.

55 Idem.
}

R. I., 1998, n. 212 
En el informe de la Secretaría de Agricultura, Industria y Comercio de 1899 se insistía en que no había en el país ninguna institución de crédito que favorezca a nuestros agricultores, cuando más necesitados están de ella ${ }^{56}$ y se insistía en que las solicitudes de apoyo para su creación no habían tenido éxito. En su estudio sobre las condiciones y posibilidades económicas y comerciales de Cuba William Clark en su importante libro sobre la situación del país a finales de la Guerra destacaba que, según opiniones autorizadas, en Cuba no existía un sistema bancario al estilo europeo o de los Estados Unidos. Que unas pocas grandes casas comerciales realizaban el negocio bancario en forma privada y otros conocidos con banqueros se dedicaban el giro de letras de cambio ${ }^{57}$.

En cuanto a la Deuda de Cuba, es conocido que fue objeto de discusión en las negociaciones para la firma del Tratado de París y la Isla fue liberada de esa enorme carga, por lo que las finanzas estatales comenzaron el proceso de reconstrucción liberadas de ella. Pero la propiedad inmueble permaneció afectada por los gravámenes acumulados, los propietarios carecían de efectivo para afrontar los gastos de reconstrucción y financiar las cosechas, de aquí que muchos se vieran obligados a entregar sus propiedades o parte de ellas para pagar sus deudas, por una parte ínfima de su valor. Esta situación propició el proceso de desnacionalización de la propiedad rústica cubana que se produjo durante las primeras décadas de este siglo.

The author discusses the repercussions of the War of Independence on the Cuban economy as a Whole. The data provided include costs per sector, their effects on exports, customs figures and collection of taxes. In addition, the author's analysis on property imposts provides the reader with information on Cuba's financial situation and that of the landowners at the time when the reconstruction of the country began.

56 Cuba. Gobernador Militar, Civil Report, La Habana, 1900, T. 7, p. 72.

57 W. ClaRCK, [17], p. 144. 